\title{
Staphylococcus-associated marginal keratitis secondary to pterygium surgery: a case report
}

\author{
Xin Liu ${ }^{1,2+}$, Xiancheng $\mathrm{Ye}^{1 \dagger}$ and Yanlong $\mathrm{Bi}^{1 *}$ (D)
}

\begin{abstract}
Background: Staphylococcus-associated marginal keratitis is an immune-mediated corneal disorder mainly secondary to chronic blepharoconjunctivitis. We report a rare case of Staphylococcus-associated marginal keratitis following pterygium excision. To the best of our knowledge, none of the previous literature has described such an acute complication after pterygium surgery.

Case presentation: We report a case of a 50-year-old woman who suffered from pterygium in the left eye and underwent pterygium surgery. After surgery, slit-lamp examination showed an incomplete ring-shaped creamy white infiltrate. Corneal pathogenic microbial detection was negative. Staphylococcus aureus was found on the upper eyelid margin of the affected eye. Therefore, she was clinically diagnosed with Staphylococcus-associated marginal keratitis. The infiltrate was gradually absorbed after steroids, topical antibiotics, and lubricant eye drops were administered. After 2 years of follow-up, neither corneal infiltrate nor pterygium recurrence was observed.

Conclusion: Staphylococcus-associated marginal keratitis is an immune reaction mainly secondary to chronic blepharoconjunctivitis, which usually activates an antigen-antibody reaction with complementary activation and neutrophil infiltration in patients sensitized to staphylococcal antigens. Early detection and treatment is of great importance. Topical steroids are effective and should be initiated early once pathogenic microbial infections are excluded. Although chronic staphylococcal blepharoconjunctivitis is a common disease, ophthalmologists should pay more attention to it to avoid potential complications.
\end{abstract}

Keywords: Pterygium excision, Staphylococcus aureus, Marginal keratitis, Blepharoconjunctivitis, Case report

\section{Background}

Pterygium is a common ocular surface disease that is usually benign, and surgery is the only curative treatment. Reported complications include keratitis, scleral ulceration, necrotizing scleritis, perforation, iridocyclitis, cataract formation, glaucoma, and scleral calcification [1]. Staphylococcus-associated marginal keratitis, also

\footnotetext{
* Correspondence: biyanlong@tongji.edu.cn

${ }^{+}$Xin Liu and Xiancheng Ye contributed equally to this work.

'Department of Ophthalmology, Tongji Hospital Affiliated with Tongji

University School of Medicine, No. 389, Xincun Road, Putuo District, Shanghai 200065, China

Full list of author information is available at the end of the article
}

called catarrhal ulcers, was first recorded by Thygeson in 1946 and is usually regarded as a complication of chronic staphylococcal blepharoconjunctivitis [2]. Staphylococcus aureus (S. aureus) plays an important role in the onset of catarrhal ulcers, which usually activate an antigenantibody reaction with complementary activation and neutrophil infiltration in patients sensitized to staphylococcal antigens $[3,4]$. To the best of our knowledge, this is the first report of Staphylococcus-associated marginal keratitis following pterygium surgery.

(c) The Author(s). 2021 Open Access This article is licensed under a Creative Commons Attribution 4.0 International License, which permits use, sharing, adaptation, distribution and reproduction in any medium or format, as long as you give appropriate credit to the original author(s) and the source, provide a link to the Creative Commons licence, and indicate if changes were made. The images or other third party material in this article are included in the article's Creative Commons licence, unless indicated otherwise in a credit line to the material. If material is not included in the article's Creative Commons licence and your intended use is not permitted by statutory regulation or exceeds the permitted use, you will need to obtain permission directly from the copyright holder. To view a copy of this licence, visit http://creativecommons.org/licenses/by/4.0/ The Creative Commons Public Domain Dedication waiver (http://creativecommons.org/publicdomain/zero/1.0/) applies to the data made available in this article, unless otherwise stated in a credit line to the data. 


\section{Case presentation}

A 50-year-old woman suffering from nasal pterygium in the left eye came to our clinic and sought pterygium surgery. The patient had no specific medical or surgical history. She had best corrected visual acuity (BCVA) of 20/ 20 in both eyes. There were no obvious abnormalities on the external eye examination, slit-lamp examination or fundus examination. Then, the patient underwent successful pterygium excision with conjunctival autografts in our clinic.

On the first day after surgery, the patient was in moderate pain with tearing and photophobia. Her BCVA was 20/20. Slit-lamp examination showed an incomplete ringshaped creamy white infiltrate with an intact corneal epithelium over the infiltrate that left a clear space between the infiltrate and limbus (Fig. 1) and was associated with mild meibomian gland obstruction (Fig. 2), conjunctival congestion, no obvious ocular discharge, quiet anterior chamber, and a normal fundus examination. Corneal scraping from the affected eye, the conjunctival sac discharge and the upper lid margin discharge in both eyes were sent for Gram and Giemsa staining and pathogenic microbial detection. The upper lid margin in both eyes was positive for $S$. aureus, but it was negative in the corneal scraping and conjunctival sac. Meibomian gland infrared photography showed partial meibomian gland loss (Fig. 2). The examination results included hematology analysis, erythrocyte sedimentation rate (ESR), C-reactive protein (CRP), rheumatoid factor, antinuclear antibody, antineutrophil cytoplasmic antibodies, TORCH infections, and T-SPOT. TB assays were all negative. Combining the above results, we clinically diagnosed the patient with Staphylococcus-associated marginal keratitis. Daily eyelid hygiene was advised, and 1\% prednisolone acetate, $0.3 \%$ levofloxacin and $0.1 \%$ sodium hyaluronate eye drops were administered 4 times a day under close observation. The infiltrate was gradually absorbed after initiation of the medication. One week later, the infiltrate was nearly absorbed and left only a mild stromal haze. After 2 years of follow-up, neither corneal infiltration nor pterygium recurrence was observed. The patient was satisfied with the treatment effect.

\section{Discussion and conclusions}

Pterygium surgery is usually thought to have a low rate of infectious complications. Nevertheless, infectious complications could unexpectedly occur a few days or even a few years after surgery. Mohammad et al. found an incidence of $2 / 1000$ for microbial keratitis after pterygium surgery [5].

Staphylococcus-associated marginal keratitis is an immune-mediated corneal disorder secondary to longstanding staphylococcal blepharoconjunctivitis, which typically manifests as a gray-white, ring-shaped infiltrate, which is always located approximately $1 \mathrm{~mm}$ inside the limbus, with a characteristic clear zone of cornea between the infiltrate and the limbus, and there is little tendency to spread centrally or peripherally [6]. The infiltrate appears first and is followed by fluorescein staining as ulceration develops [7].

To the best of our knowledge, Staphylococcus-associated marginal keratitis could occur in an acute, subacute or chronic onset. In some cases, the disease can be recurrent with longstanding staphylococcal blepharoconjunctivitis. There is no doubt that we should distinguish this disease from direct infectious keratitis. Microbial

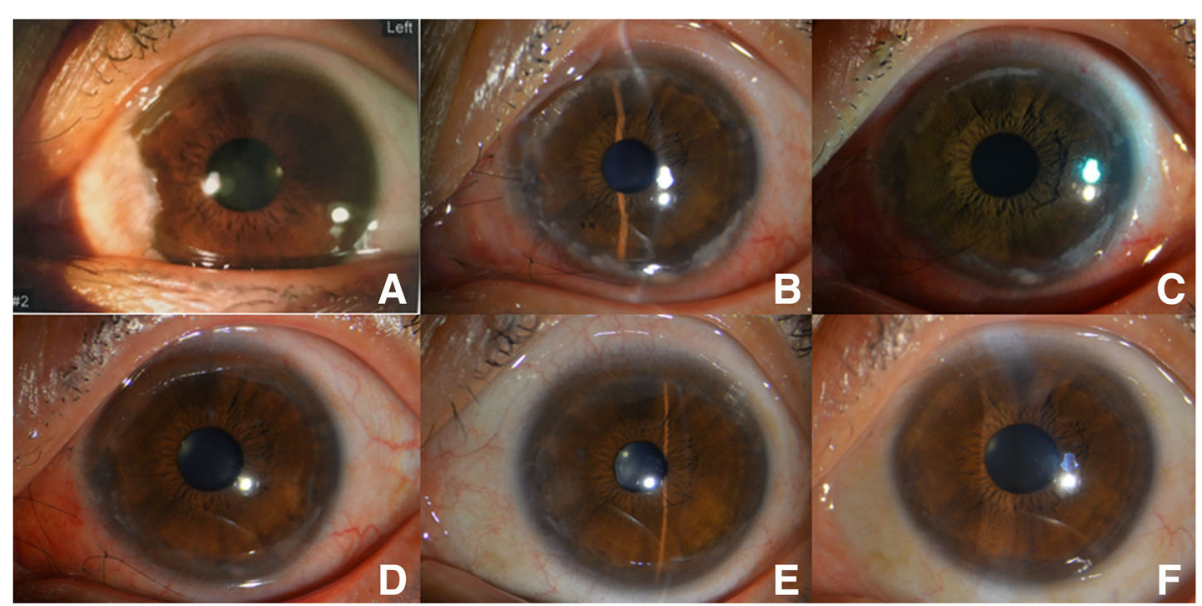

Fig. 1 Slit-lamp examination. a Preoperative slit-lamp photography of the left eye. b Slit-lamp photography of the left eye 1 day after pterygium excision with conjunctival autografts. Note the incomplete ring-shaped creamy white infiltrate with an intact corneal epithelium over the infiltrate that left a clear space between the infiltrate and limbus. c Two days after treatment. $\mathbf{d}$ Eight days after treatment. Note the infiltrate being gradually absorbed. e Three months after treatment. Note that there was a mild stromal haze peripherally. $\mathbf{f}$ Fifteen months after treatment. Note that the cornea is clear, and neither corneal infiltration nor pterygium recurrence is seen 


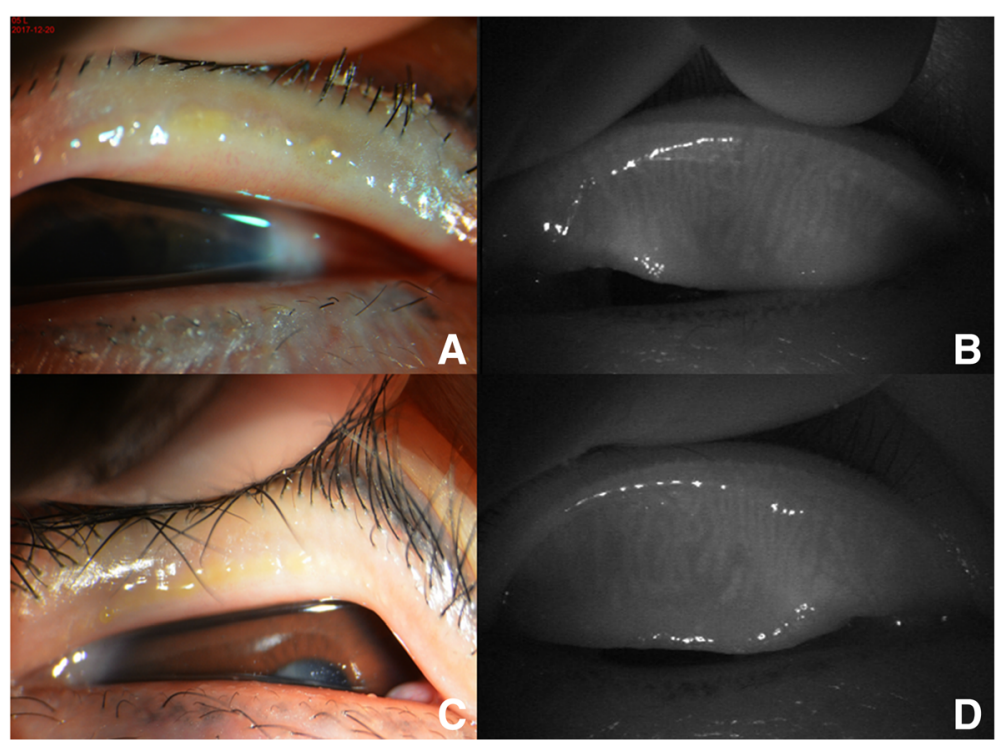

Fig. 2 Slit-lamp and meibomian gland infrared photography. a A slit lamp showed meibomian gland obstruction and yellow discharge of the left upper eyelid. b Meibomian gland infrared photography showed partial meibomian gland loss of the left upper eyelid. c A slit lamp showed meibomian gland obstruction and yellow discharge from the right upper eyelid. $\mathbf{d}$ Meibomian gland infrared photography showed partial meibomian gland loss of the right upper eyelid

keratitis after pterygium surgery usually occurs in the operative site and is accompanied by severe pain, conjunctival congestion, and ocular discharge. The gold standard of diagnosis is the detection of pathogens and the effectiveness of antibiotic eye drops. Therefore, combined with the characteristics of our case, we clinically diagnosed this patient with Staphylococcus-associated marginal keratitis.

In 1946, Thygeson isolated S. aureus from the lids of 133 of 156 patients with catarrhal keratoconjunctivitis [2]. Hogan et al. noted that lid cultures usually grew $S$. aureus in marginal keratitis, but their corneal cultures were negative for bacteria [8]. This reveals that the lesion is probably not triggered by direct infection of the cornea but by a hypersensitivity reaction, in which antigen-antibody reactions with complement activation and neutrophil infiltration in patients are sensitized to staphylococcal antigens [9]. Ueta et al. suggested that the $S$. aureus present in the lid margin, rather than the conjunctival sac, was more important for the development of Staphylococcus-associated marginal keratitis [10]. Rao et al. proposed that increased expression of meibomian secretions and bacterial toxins after manipulation of the lid margin could trigger immunological reactions with infiltration. If this theory is true, there should be a more marginal infiltrate after ocular surgery, since lid inflammation is common [11].

Interestingly, Ueta et al. found the same clone of $S$. aureus in the margin of the unaffected eye [10]. In the case presented herein, the same clone of $S$. aureus was also found in the upper lid margin and it was negative in the conjunctival sac of the unaffected eye. This revealed that in addition to the existence of $S$. aureus on the lid margin, we need to assume that other factors, such as the patients' high sensitivity to $S$. aureus, chemical or physical stimulation, differences in the number of bacteria between the affected eye and unaffected eye, etc., may be trigger factors for the initiation of Staphylococcus-associated marginal keratitis.

In summary, the incidence of infectious keratitis following pterygium excision is low, and ophthalmologists should be aware of potential infectious complications that can have dramatic outcomes. Staphylococcus-associated marginal keratitis is a rare surgical complication after pterygium excision, and $S$. aureus colonization of the lid margin may be one of the most important causes. Topical steroids have a significant effect and should be initiated as soon as possible to minimize the lesions once direct infections by pathogenic microorganisms are excluded. In most cases, the patients had a favorable prognosis. Since there are many people with longstanding staphylococcal blepharoconjunctivitis, it is clear that only a few of them have developed marginal keratitis. Therefore, the pathogenesis of Staphylococcus-associated marginal keratitis deserves further study.

\section{Abbreviations}

S aureus: Staphylococcus aureus; BCVA: Best corrected visual acuity; ESR: Erythrocyte sedimentation rate; CRP: C-reative protein 


\section{Authors' contributions}

LX and XC were involved in collecting clinical data, the literature search, preparation and editing of the manuscript. YL helped managed the patient and review of the manuscript. All authors have read and approved the manuscript.

\section{Funding}

This report was supported by the National Natural Science Foundation of China (Grant Number: 82070920). The funding organizations had no role in the design or conduct of this research.

\section{Availability of data and materials}

Not applicable.

\section{Declarations}

\section{Ethics approval and consent to participate}

Institutional review board approval from the Tongji Hospital Affiliated with Tongji University School of Medicine was obtained and the tenets of the Declaration of Helsinki were followed.

\section{Consent for publication}

Written informed consent to publication (including images, personal and clinical details of the participants) has been obtained from the patient.

\section{Competing interests}

The authors declare that they have no competing interests.

\section{Author details}

'Department of Ophthalmology, Tongji Hospital Affiliated with Tongji University School of Medicine, No. 389, Xincun Road, Putuo District, Shanghai 200065, China. 'Department of Ophthalmology, Guizhou Provincial People's Hospital, Guiyang, Guizhou, China.

Received: 16 November 2020 Accepted: 17 March 2021

Published online: 31 March 2021

\section{References}

1. Hirst LW. Recurrence and complications after 1,000 surgeries using pterygium extended removal followed by extended conjunctival transplant. Ophthalmology. 2012;119(11):2205-10. https:/doi.org/10.1016/j.ophtha.2012.06.021.

2. Thygeson P. Marginal corneal infiltrates and ulcers. Trans Am Acad Ophthalmol Otolaryngol. 1947;51:198-209.

3. Mondino BJ, Brown SI, Rabin BS. Role of complement in corneal inflammation. Trans Ophthalmol Soc UK. 1978:98(3):363-6.

4. Mondino BJ, Kowalski R, Ratajczak HV, Peters J, Cutler SB, Brown SI. Rabbit model of phlyctenulosis and catarrhal infiltrates. Arch Ophthalmol. 1981; 99(5):891-5. https://doi.org/10.1001/archopht.1981.03930010891022.

5. Soleimani M, Tabatabaei SA, Mehrpour M, et al. Infectious keratitis after pterygium surgery. Eye. 2020;34:986-8.

6. Özcura F. Successful treatment of staphylococcus-associated margina keratitis with topical cyclosporine. Greafes Arch Clin Exp Ophthalmol. 2010; 248(7):1049-50. https://doi.org/10.1007/s00417-009-1290-4.

7. Mondino BJ. Inflammatory diseases of the peripheral cornea. Ophthalmology 1988:95(4):463-72. https:/doi.org/10.1016/S0161-6420(88)33164-7.

8. Hogan MJ, Diaz-Bonnet V, Okumoto M, et al. Experimental staphylococcic keratitis. Investig Ophthalmol. 1962;1:267-72.

9. Smolin G, Okumoto M. Staphylococcal blepharoconjunctivitis. Arch Ophthalmol. 1977;95(5):812-6. https://doi.org/10.1001/archopht.1977.044 50050090009

10. Ueta M, Sotozono C, Takahashi J, Kojima K, Kinoshita S. Examination of Staphylococcus aureus on the ocular surface of patients with catarrhal ulcers. Cornea. 2009;28(7):780-2. https://doi.org/10.1097//CO.0b013e3181 99f8c6.

11. Rao SK, Fogla R, Rajagopal R, et al. Bilateral corneal infiltrates after excimer laser photorefractive keratectomy. J Cataract Refract Surg. 2000;26(3):456-9. https://doi.org/10.1016/50886-3350(99)00348-X.

\section{Publisher's Note}

Springer Nature remains neutral with regard to jurisdictional claims in published maps and institutional affiliations.

Ready to submit your research? Choose BMC and benefit from:

- fast, convenient online submission

- thorough peer review by experienced researchers in your field

- rapid publication on acceptance

- support for research data, including large and complex data types

- gold Open Access which fosters wider collaboration and increased citations - maximum visibility for your research: over $100 \mathrm{M}$ website views per year

At $\mathrm{BMC}$, research is always in progress. 